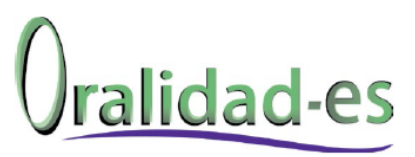

REVISTA DE LA RED IBEROAMERICANA DE ESTUDIOS

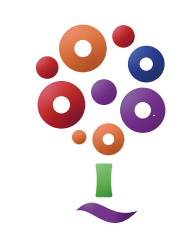

\title{
Un diálogo sobre el estudio de caso como un tipo de investigación
}

\author{
A dialogue about the case study as a type of research
}

\author{
Laura Daniela Castañeda-Gutiérrez \\ lauradcastanedag@gmail.com \\ Escuela Colombiana de Rehabilitación, Colom- \\ bia
}

\author{
Mirta Yolima Gutiérrez-Ríos \\ yolimagr@yahoo.es \\ Escuela Normal Superior María Montessori, \\ Bogotá, Colombia
}

Castañeda-Gutiérrez, L. D. \& Gutiérrez-Ríos, M. Y. (2017). Un diálogo sobre el estudio de caso como un tipo de investigación. Oralidad-es, 3(6), 48-52. https://revistaoralidad-es.com/index.php/ro-es/article/view/86

Fecha de recepción: 20 de marzo de 2017 / Fecha de aprobación: 20 de noviembre de 2017 
Documentar e interpretar lo que un grupo o población "piensa y hace", ha sido una práctica habitual en la investigación.

Caso: La habitual cita en el café Windsor de la Jiménez, que fue propiedad de los hermanos Luis y Agustin Nieto Caballero, era para Helen Simons, docente investigadora con una amplia experiencia en estudios de caso, una forma de recobrar su idealismo febril de "tener tiempo para pensar". El aroma del café la alejaba de la agitada vida citadina y esa mezcla sutil de bohemia y prolongadas e impetuosas conversaciones lograba en ella un efecto kafkiano, sostenido por la caldeada atmósfera que alcanzaba a crear los habituales de aquel café libro. Esta vez la cita era con Laura una maestra, quien años atrás había acudido a ella, cuando se formaba como Normalista Superior en busca de asesoría sobre cómo hacer una investigación mediante el estudio de casos y ahora regresaba con muchos deseos de compartirle su experiencia.

Fue inevitable que las dos repararan en cada detalle de aquel universo paradisiaco del café Windsor, las viejas caricaturas de Rendón que criticaban la hegemonía del partido conservador colombiano, prolongada hasta la década del 30; las revistas emblemáticas de Los nuevos y la revista Universidad de Germán Arciniegas, famosa por los ensayos de Baldomero Sanín Cano y Luis López de Mesa.

De la pesquisa de éstas y otras situaciones que diligentemente describieron, llegaron a la conclusión de lo interesante que resultaría el estudio de este particular lugar, pues siendo, los café libro, espacios tan desconocidos para unos y tan controvertidos para otros, podrían constituirse en una "unidad singular de análisis", porque no solo guardan los secretos de los poetas y sus contertulios sino épocas de nuestra cultura construidas desde la elocuencia del diálogo y la discusión académica, esa que posibilita una comprensión crítica del discurso y la acción humana. Sin duda, aqui se fraguaron las verdaderas gestas libertadoras, aquellas que buscaban liberar el espíritu, esas poéticas incendiarias, cuyas peculiares raíces residian en el pensamiento de Rousseau, Diderot, Voltaire o D’Alembert.

Laura: El café "es el dulce hogar para los que el dulce hogar es un horror”, decía Polgar en 1926 refiriéndose al Café Central de Viena, seguramente él si tenía muy clara la riqueza estética e intelectual que emanaba de los húsares de la palabra que habitaron estos lugares. ¿Te imaginas?, ¡un estudio de caso sobre los café libro del centro de Bogotá! En otra época me hubiera parecido una pérdida de tiempo o quizás hubiera caído en uno de los cinco malentendidos que refiere el investigador danés Flyvbjerg en su libro, considerar que, "no podemos generalizar a partir de un solo caso y, por lo tanto, el estudio de un solo caso no puede contribuir al desarrollo científico".

Helen: Sin duda, todo aquel que llega a los estudios de caso se tropieza frecuentemente con los escépticos que los tildan de pseudo investigación o aquellos metodólogos como Hans Eysenck en 1976, quien los consideraba un método para producir anécdotas, aunque luego él mismo comprendió que los casos individuales encarnaban aprendizajes valiosos. Es inevitable que al comienzo sientas cierta desconfianza por este tipo de investigación, de ahí que surjan muchos cuestionamientos al respecto. Recuerdo cuando empezaste a hacer tu tesis y me escribiste aquella carta con preguntas tan acuciantes. En esas líneas yo sentí que tu desazón era de tal magnitud y tus cuestionamientos tan complejos que quizás la lectura de un texto estructurado podría hacer que otras voces llegaran a ti y al resonar en tu cabeza, te inquietaran y te motivaran a la búsqueda, a la discusión y ¿por qué no?, a liberarte de esas inseparables sombras que te rodeaban. 
Laura: Ah, sí, luego descubrí que las sombras no eran otra cosa que mi ingenuidad propia de ese momento. En realidad logré superar varios malentendidos prontamente, motivada por modelos como el Freud o Piaget que nacieron y se nutrieron del estudio de casos o el de Galileo: si él había conseguido refutar la milenaria teoría de Aristóteles respecto a la gravedad, mediante un profundo razonamiento y un experimento práctico, logrando que este caso fuera decisivo para el desarrollo de la física, quería decir que la clave estaba en la elección estratégica del caso por parte del investigador, de ésta dependía el nivel de aporte a la construcción de conocimiento y al desarrollo científico.

Helen: ¡Huuy!, ¡qué bien!

Laura: Algo que realmente me quitaba el sueño en aquella época era la idea de cómo formar sólidamente mi propia concepción sobre el estudio de caso, de tal forma que contara con suficientes elementos de juicio para convencer a mi director de tesis - un reconocido hombre de ciencia que había dedicado toda su vida a examinar información verbal obtenida a través de baterías de mediciones y a controlar la naturaleza social mediante patrones generales que rechazaban lo diverso, particular y específico- de la pertinencia del estudio de caso para la inquietud investigativa que merodeaba mi mente en aquellos años cuando realizaba mi práctica pedagógica en una escuela rural.

Helen: Bueno, no podemos perder de vista, que, como yo misma lo viví, el estudio caso incursionó con fuerza en el campo educativo hacia la década de los setenta, especialmente en el Reino Unido y en el país de tío Sam que...
Laura: ... ja propósito!... ¡es un personaje prototipo de los estudios de caso!, para el mundo, él no simboliza un país, sino que él en sí mismo, es el país (risas).

Helen: Eso... En aquella época recién llegaba yo a Inglaterra a impartir mi cátedra de evaluación e investigación educativa y fui testigo de la batalla que iniciaban el estudio de caso y la etnografía en la comprensión de la experiencia de innovación curricular y cómo el peso de la "uniformidad y predictibilidad” de la tradición positivista aplastaba rápidamente cualquier intento por demostrar su validez. Pero aun así... se creó una especie de "revolución metodológica" que de manera sosegada fue aportando copiosa literatura sobre una investigación que echaba mano de procesos cualitativos, cuantitativos y mixtos para analizar una unidad integral y así resolver un problema, probar una hipótesis o desarrollar una teoría. Y de este modo se fue haciendo visible el estudio de caso en otros campos como la medicina, el trabajo social, derecho y la psicología.

Laura: ¡Ahí está el carácter multidisciplinario del estudio de caso!, pese a que su base es sustancialmente social y antropológica, no lo hace exclusivamente cualitativo, por el contrario, se erige como una interesante alternativa que al decir de algunos investigadores, combina datos e información cuya descripción y análisis extensivo posibilitan el entendimiento comprehensivo de un "todo" y su contexto. Esa capacidad de complementariedad es lo que en realidad legitima su existencia. ¡Nada más sabio que entender que el estudio de caso no es sinónimo de método cualitativo! y que, no es cierto que los estudios de caso solo llegan a la generación de hipótesis! Se trata de aprender a examinar cómo es su accionar, cómo se desarrolla en sí mismo... ahí ha ganado el apelativo de caso y ha logrado su objetivo de generalización. 
Helen: Esa relevancia universal es la piedra en el zapato para aquellos que se quedaron anclados en la dualidad de las tradiciones investigativas y a los que aún les cuesta admitir que el estudio de caso no es una elección metodológica, sino una apuesta por la elección de un objeto, por la singularidad de un fenómeno localizado en un tiempo y un espacio concreto, al cual le cabe el razonamiento heurístico, capaz de obtener cambios en los sujetos y en sus auténticos contextos... otra cosa es que la elección del método guarde cierta relación. Siempre he sostenido que el estudio de caso es una investigación exhaustiva realizada desde múltiples perspectivas, lo cual implica la integración de varios métodos.

Laura: Fue precisamente esta cuestión de si el estudio de caso era un método, una estrategia, un diseño de investigación o un enfoque, otra de mis preocupaciones intelectuales. Pese a la diversidad de posturas, tú insistías en que el estudio de caso debía asumirse como un enfoque porque de suyo tenía una intención investigativa y un propósito metodológico y no como un método porque éste correspondía a las técnicas de recolección de información, ni a una estrategia porque ésta representaba un proceso de planeación, realización, análisis e interpretación; sin embargo, otros investigadores como la profesora colombiana María Eumelia Galeano en el 2004, me dieron argumentos contundentes para entender que el estudio de caso puede ser una estrategia de investigación.

Helen: Mi querida Laura, importa mucho lo que tú hayas logrado dilucidar.

Laura: En las largas discusiones con mi tutor, llegamos a un relativo acuerdo: considerar los estudios de casos como un tipo de investigación porque una de las características que sin duda los distingue es su objeto de estudio, "es el interés en el objeto lo que lo define”, decía Stake en 1995. Este objeto se puede abordar desde diferentes métodos y diversas técnicas -análisis documental, entrevista, observación, encuesta, entrevista en profundidad...- mientras que, si nos referimos al método o forma de abordaje sería una investigación documental, histórica... Concluimos que si asumíamos el estudio de caso como un enfoque corríamos el riesgo de confundirlo con enfoque metodológico o definir su abordaje desde métodos cuantitativos -experimental, preexperimental, cuasiexperimental- cualitativos -etnografía, etnometodología, método histórico, etc.- y alternativos o participativos -IAP e IA-.

Helen: Hum... entiendo. No pretendo disuadirte de tu certeza, pues es así como todos los que trabajamos en este mundo de las ideas y el conocimiento, vamos tejiendo nuestros propios saberes desde los elementos de control que propongo en el memorando 1 de mi libro sobre estudio de caso, es definir sin rodeos su concepto, tipo y justificación y si no estoy mal, digo algo como: "No dediques mucho tiempo a argumentar por qué no has optado por otros sistemas de investigación. Solo te podría ser útil hasta cierto punto. Es más importante argumentar de forma convincente por qué el estudio de caso es el más adecuado para el tema que vas a investigar”. Bueno, después de eso lo que haría falta sería que estos lugares $\mathrm{u}$ otros que existen con una atmósfera menos intelectual que la de un café libro como los parques, las plazas de mercado, las fondas, las bodegas sean frecuentadas por investigadores.

Laura: Ajá... ¡De eso se trata! De buscar una presencia más activa en el proceso investigativo, salir de las aulas y los centros de documentación para ir en busca de situaciones y personas que nos brinden su percepción directa de la realidad, vivir el trabajo de campo a plenitud; esto implica reflexionar sobre la perspectiva metodológica 
y las condiciones que se requieren para lograr una interacción real y un trabajo conjunto con la población seleccionada para la investigación.

Helen: Pasando a lo mundano, Laura, ya creo que es hora de salir, los meseros ya empiezan a limpiar este mítico lugar.

Al lado de las dos tazas de café quedó un lapicero y dos hojas con preguntas escritas con tinta de pluma de color negro grisáceo: Cada conversación tiene su propio espíritu dialógico y el lenguaje que fluye, encarna su propia verdad, aunque no sea placentera. 